\title{
LA FUNCIÓN DE LA ORIENTACIÓN AL ERGATIVO EN EL DISCURSO NARRATIVO MALECU
}

\author{
Haakon Stensrud Krohn
}

\begin{abstract}
RESUMEN
En este artículo se analiza el uso de la orientación al ergativo en el discurso narrativo tradicional malecu, de manera cuantitativa y cualitativa, desde la perspectiva de la gramática funcional. Los análisis indican que la construcción se puede explicar mejor como un recurso empleado principalmente para evitar la posible ambigüedad en cuanto al caso gramatical de los sintagmas nominales que codifican los participantes ergativos.
\end{abstract}

Palabras clave: Malecu, ergatividad, topicalidad, sintaxis, análisis del discurso.

\section{ABSTRACT}

This paper analyzes the use of the so-called ergative orientation in traditional narrative discourse in Maleku, both quantitatively and qualitatively, within the functionalist framework. The analyses indicate that this construction can be explained as a device principally used to avoid the possible ambiguity regarding the grammatical case of the nominal phrases that codify the ergative participants.

Key words: Maleku, ergativity, topicality, syntax, discourse analysis.

\section{Introducción}

El malecu, también conocido como guatuso, es una lengua que pertenece a la familia lingüística chibchense y es hablada por los malecus en el cantón de Guatuso en la provincia de Alajuela en el norte de Costa Rica. Esta lengua, cuya marcación de casos es ergativoabsolutiva, presenta una construcción muy particular, llamada "orientación al ergativo" por Constenla $(1986,1998)$, la cual se emplea como una estrategia alternativa para codificar los participantes ergativos. En las cláusulas orientadas al ergativo, el verbo se flexiona solo para

ML. Haakon Stensrud Krohn. Profesor. Escuela de Filología, Lingüística y Literatura. Universidad de Costa Rica. Correo electrónico: hkrohn@gmail.com

Recepción: 02- 05- 2013

Aceptación: 28- 05- 2013 
la persona del absolutivo, mientras que el actante ergativo es codificado por medio de un sintagma posposicional constituido por un sintagma nominal seguido por la posposición - $t i$.

La función de esta construcción ha sido analizada y descrita por Constenla (1986), pero a partir de un corpus muy limitado, de solo 30 cláusulas. En este artículo se presenta un análisis más detallado del fenómeno, realizado con base en un corpus mucho más amplio, con el fin de entender mejor la función de la orientación al ergativo.

El análisis consiste en una parte cuantitativa y otra cualitativa. La perspectiva teórica que se sigue es la de la gramática funcional, específicamente el funcionalismo tipológico, tal y como es presentado por Givón (2001a, 2001b). El funcionalismo es una corriente lingüística empirista y se opone a teorías de carácter mentalista, como la gramática generativa. La perspectiva funcionalista se basa en que la relación entre la forma y el significado a nivel gramatical no es arbitraria, sino intencional. Sin embargo, existe arbitrariedad en la codificación de conceptos básicos por medio de palabras y sonidos (Givón 2001a: 4).

\section{La codificación de los participantes discursivos en malecu}

El malecu presenta una marcación de casos ergativo-absolutiva, sistema que se codifica en la conjugación de los verbos, de modo que existe una serie de prefijos para indicar la persona gramatical del absolutivo y otra para indicar la del ergativo (Constenla 1998: 69-73). En las cláusulas transitivas no orientadas al ergativo, los dos argumentos verbales son codificados mediante sus respectivos prefijos verbales.

Los prefijos verbales de persona son los siguientes (sin incluir los varios alomorfos que presentan):

Cuadro 1. Los prefijos verbales de persona en malecu.

\begin{tabular}{|l|l|l|}
\hline & Absolutivos & Ergativos \\
\hline $1^{\text {a }}$ persona exclusiva & na- & rra- \\
\hline $1^{\text {a }}$ persona inclusiva & ma- & ri- \\
\hline $2^{\text {a }}$ persona & mi- & rrifa- \\
\hline $3^{\text {a }}$ persona & i- & rri- \\
\hline
\end{tabular}

También, pueden aparecer sintagmas nominales completos o pronombres correferenciales con las series de prefijos; estos elementos no llevan ninguna marcación morfológica de caso. Los sintagmas nominales se emplean para especificar semánticamente al referente, por lo que su uso depende principalmente de la identificabilidad de este, mientras que los pronombres parecen cumplir otras funciones, tales como dar énfasis o presentar un contraste (Krohn 2012). En el presente artículo, el uso de un sintagma nominal o un pronombre será tratado como una mención "explícita" del referente. Por su parte, Constenla (1998) utiliza el término "detalladores" para aludir a estos elementos.

De acuerdo con Constenla (1998: 208), la posición básica de todos los sintagmas nominales detalladores de la proposición verbal es a la izquierda de la forma verbal. Sin embargo, si bien los pronombres siempre se colocan en dicha posición, las otras formas nominales pueden desplazarse al lado derecho del verbo. Cuando dos formas nominales detalladoras aparecen del lado izquierdo de la forma verbal, la del absolutivo tiene que ubicarse más cerca del verbo (con algunas excepciones muy poco frecuentes). Por esta razón, nunca hay ambigüedad en cuanto a su caso gramatical cuando ambos elementos aparecen en su 
colocación básica. Por lo tanto, la oración en el ejemplo 1, tomada de Constenla (1998: 142), tiene solo una interpretación con respecto a los referentes de las formas nominales:

(1) ochápacá curíjurí rri-cuá-nhe

hombre mujer (3)-3erg-ver-MR ${ }^{1}$

"el hombre vio a la mujer"

En cambio, cuando una o dos de las formas nominales detalladoras aparecen del lado derecho de la forma verbal, sí se puede producir una ambigüedad para el oyente, ya que, en este caso, el orden no explicita cuál es el papel semántico (agente o paciente) correspondiente a cada uno de los sintagmas nominales. El oyente, en ocasiones, puede resolver dicha ambigüedad gracias al contexto o a las propiedades semánticas o el grado de agentividad de los referentes. Por ejemplo, la cláusula en 2, tomada de Constenla (1998: 142), normalmente se interpretaría como 'el hombre vio la casa' y no como 'la casa vio al hombre', puesto que ochápaca 'hombre' ocupa una posición más alta en la jerarquía de agentividad que ú 'casa'.

(2) i-rri-cuá-nhe ochápacá ú

3-3erg-ver-MR hombre casa

"el hombre vio la casa"

Sin embargo, hay casos en los cuales los dos actantes poseen el mismo grado de agentividad, y el contexto no ayuda a desambiguar. Cláusulas como las que se presentan en 3 y 4, tomadas de Constenla (1998: 142), pueden interpretarse como 'el hombre vio a la mujer' o como 'la mujer vio al hombre':

(3) i-rrí-cuá-nhe curíjurí ochápacá

3-3erg-ver-MR mujer hombre

"el hombre vio a la mujer" / "la mujer vio al hombre"

(4) curíjurí rri-cuá-nhe ochápacá

mujer (3)-3erg-ver-MR hombre

"el hombre vio a la mujer" / "la mujer vio al hombre"

También puede existir ambigüedad cuando solo uno de los dos argumentos de un verbo transitivo es explicitado y los dos argumentos verbales son de tercera persona, lo cual es muy frecuente. Por ejemplo, en 5, es imposible determinar, sin conocer el contexto, si ochápacá 'el hombre' es el participante ergativo o absolutivo del evento verbal sin conocer el contexto:

(5) ochápacá rri-cuá-nhe

hombre (3)-3erg-ver-MR

"el hombre lo/la vio" / "vio al hombre"

Cuando ocurre un desplazamiento a la derecha, muchas veces el elemento nominal se duplica por medio de un tema nominal sustitutivo (más frecuentemente ní), el cual se coloca en la posición que sería la básica del elemento desplazado (a la izquierda de la forma verbal), tal y como se muestra en el siguiente ejemplo (Constenla 1998: 216):

(6) ní maráma rra-cuá-nhe Chimpacá juérri Polhpolh

3 PL (3)-1erg-MR Chimpacá y Polhpolh

"los vi a Chimpacá y Polhpolh" 


\section{Las cláusulas orientadas al ergativo}

Como ya se ha mencionado, existe otra alternativa gramatical en el malecu para expresar el participante ergativo, la cual Constenla (1986, 1998) denomina "cláusulas transitivas orientadas al ergativo". En estas, el actante ergativo se codifica mediante un sintagma posposicional con la posposición - $t$. Como el verbo no se flexiona para la persona del ergativo en las cláusulas orientadas al ergativo, en este artículo se tratará dicha construcción como una voz intransitivadora. En otras palabras, las cláusulas orientadas al ergativo serán clasificadas como cláusulas sintácticamente intransitivas (pero semánticamente transitivas).

A continuación se presentan dos ejemplos para ilustrar la diferencia entre las cláusulas orientadas al ergativo y las no orientadas:

(7) No orientada:

ma-rrá-cuá-nhe

2-1Ierg-ver-MR

"te vi"

(Constenla 1998: 71)

(8) Orientada:

ton-ti mi-cuá-nhe

1Esg-ERG 2-ver-MR

"yo te vi"

(Constenla 1998: 144)

El sintagma posposicional ergativo que aparece obligatoriamente en las cláusulas orientadas al ergativo siempre tiene que colocarse al lado izquierdo de la forma verbal, como en el ejemplo 9. El sintagma posposicional ergativo tiene que colocarse a la izquierda de la forma detalladora del absolutivo cuando esta última aparece del lado izquierdo del verbo, como se aprecia en el ejemplo 10.

(9) curíjurí chumá-ti ochápacá cuá-nhe mujer CONM-ERG hombre (3)-ver-MR

"la pobre mujer vio al hombre"

(Constenla 1998: 144)

(10) puráni epéme ní-ti orróqui uráje

porque NEG este-ERG cosa (3)-saber.MR

"porque ella no sabía (cosas)"

(Constenla, Castro y Blanco 1993: 69;94)

Un sintagma nominal que codifique un participante ergativo en una cláusula orientada al ergativo también puede desplazarse a la derecha del verbo. En tales casos, al lado izquierdo del verbo se incluye un pronombre sustitutivo correferencial con el elemento desplazado, como se observa en 11 (Constenla, Castro y Blanco 1993: 75;298):

(11) Ta-cá ní-t i-quí-ye Tócu

y-S este-ERG 3-decir-MR dios

"Y le dijo el dios" 
Según Constenla, las cláusulas orientadas al ergativo son construcciones que se emplean para indicar mayor topicalidad del elemento ergativo. Este autor afirma que:

[...] las cláusulas transitivas adoptan la forma orientada al ergativo, cuando éste representa un participante en el hecho narrado que es al mismo tiempo 'nuevo' y el tópico de una de las cláusulas que pertenecen a la línea argumental básica de la narración. (1986: 126)

Aquí, Constenla emplea el término "tópico" con el significado de "aquel elemento particular escogido como punto de partida y acerca del cual se añade conocimiento en la oración" (1986: 121). Clasifica un participante como "nuevo" cuando se introduce o se reintroduce como tópico. De acuerdo con este autor (1998: 144), parece ser un hecho universal que la información nueva suele ser introducida por medio del actante absolutivo en las lenguas ergativas, por lo que el malecu emplea una construcción más marcada cuando es el caso contrario.

\section{Corpus analizado}

El corpus analizado para el presente trabajo consiste en diez narraciones tradicionales en malecu, específicamente las primeras diez de las publicadas en Constenla, Castro y Blanco $(1993)^{2}$. El corpus incluye un total de 1330 cláusulas.

Todas las narraciones son clasificadas por Constenla dentro del género de pláticas tradicionales (marácunúca). Dado que las narraciones en malecu presentan varios rasgos que las distinguen del estilo conversacional, sobre todo el paralelismo (repetición de la misma idea) y la estructuración en versos y estrofas, es importante tener en cuenta que los resultados de los análisis pueden diferir considerablemente de los que se obtendrían con una investigación en la que se analicen discursos conversacionales en el mismo idioma.

En Constenla, Castro y Blanco (1993), las líneas (que muchas veces no corresponden a cláusulas) están enumeradas. Las referencias de los ejemplos tomados del corpus que se presentan en este trabajo incluyen el número de la página en la que se encuentra en el libro original y el número de línea, separados por punto y coma. Por ejemplo, Constenla, Castro y Blanco (1993: 72;104) significa la línea número 104 del corpus, la cual se encuentra en la página 72. Constenla, Castro y Blanco (1993: 111;1572-1573) se refiere a las líneas 1572-1573 del corpus, que se encuentran en la página 111 del libro.

Las traducciones libres al español de los ejemplos en malecu son, en la mayoría de los ejemplos, las proporcionadas por Constenla. Sin embargo, en algunos casos se han modificado para reflejar el significado más literalmente con la intención de facilitar la comprensión de los ejemplos.

\section{Análisis cuantitativo}

\subsection{Limitaciones de estructura argumental preferida}

Como primer paso en el análisis cuantitativo, se contó el número de veces que, en el corpus, los argumentos verbales ergativos y absolutivos son explicitados mediante un sintagma nominal completo o un pronombre. Recuérdese que los participantes ergativos en las cláusulas orientadas al ergativo no se clasifican como argumentos verbales, ya que el verbo no concuerda con la persona del ergativo cuando la cláusula es orientada al ergativo. 
Du Bois (1987) establece determinados principios relacionados con la expresión de argumentos verbales. Con respecto a lo que él denomina "limitaciones de estructura argumental preferida", afirma que las lenguas tienden a presentar solo un argumento léxico en cada cláusula y a evitar el uso de formas léxicas en el argumento verbal ergativo. Esto lo relaciona con el hecho de que solo se suele introducir un nuevo participante en cada cláusula y con que los nuevos participantes normalmente aparecen en caso absolutivo. Este lingüista no menciona si los pronombres también tienden a ser evitados en el argumento verbal ergativo. Debido a esta incertidumbre, se llevaron a cabo dos conteos en el presente estudio: uno del número de argumentos léxicos (sin incluir los pronombres), y otro del número de argumentos explícitos (incluyendo tanto los sintagmas nominales completos como los pronombres).

El número de argumentos verbales ergativos y absolutivos expresados por medio de una estrategia léxica (sintagma nominal completo), junto con su distribución porcentual, así como el de los argumentos expresados con pronombre o con prefijo verbal sin elemento detallador ("no léxico") se aprecia en el cuadro 2.

Cuadro 2. Expresión léxica y no léxica de los argumentos verbales en el corpus.

\begin{tabular}{|l|l|l|l|l|}
\hline & \multicolumn{2}{|c|}{ Ergativo } & \multicolumn{2}{c|}{ Absolutivo } \\
\hline Léxico & 9 & $1,8 \%$ & 487 & $36,6 \%$ \\
\hline No léxico & 479 & $98,2 \%$ & 843 & $63,4 \%$ \\
\hline
\end{tabular}

En el cuadro 3 se presentan los números de argumentos verbales ergativos y absolutivos expresados de manera explícita, es decir, mediante un sintagma nominal completo o un pronombre, junto con su distribución porcentual.

Cuadro 3. Expresión explícita y no explícita de los argumentos verbales en el corpus.

\begin{tabular}{|l|l|l|l|l|}
\hline & \multicolumn{2}{|c|}{ Ergativo } & \multicolumn{2}{c|}{ Absolutivo } \\
\hline Explícito & 12 & $2,5 \%$ & 566 & $42,6 \%$ \\
\hline No explícito & 476 & $97,5 \%$ & 764 & $57,4 \%$ \\
\hline
\end{tabular}

Se puede observar que el argumento verbal se expresa por medio de un sintagma nominal o un pronombre personal en muy pocas ocasiones, comparado con el argumento absolutivo: solo un 2,5\% de los argumentos ergativos son explícitos, lo cual contrasta con el 42,6\% de argumentos absolutivos explícitos.

El bajo número de argumentos ergativos expresados mediante pronombres personales (solo 3 en todo el corpus) indica que, en malecu, no solo se tiende a evitar los argumentos verbales ergativos léxicos (sintagmas nominales completos), sino que también se suelen omitir los pronombres personales en la codificación de este argumento verbal.

El número de expresiones explícitas de los argumentos verbales ergativos en el corpus es tan bajo comparado con el de los argumentos absolutivos que difícilmente se puede explicar solamente por el hecho de que los nuevos participantes normalmente aparecen en caso absolutivo. Más bien, parece que el hablante emplea una estrategia para evitar casi todos los argumentos verbales ergativos, a saber, la orientación al ergativo. En el corpus hay un total de 68 cláusulas orientadas al ergativo, en las cuales, como se ha señalado, el participante ergativo siempre es explícito. 
Parece que un motivo central para omitir los argumentos verbales ergativos es el de eliminar la posible ambigüedad que existe en cuanto al caso gramatical de los referentes, como se pudo apreciar en los ejemplos 3, 4 y 5. De esta manera, en una cláusula orientada al ergativo, la posposición -tí funciona para indicar que el elemento al que se une codifica el participante ergativo y no el absolutivo. En otras palabras, cuando el participante ergativo debe explicitarse por medio de un sintagma nominal completo (normalmente debido a su baja identificabilidad) o un pronombre personal (como recurso enfático o contrastivo, entre otros), el hablante casi siempre decide expresar el evento verbal mediante una cláusula orientada al ergativo para que quede claro que el sintagma nominal que codifica el participante ergativo no se refiere al absolutivo. Esto también podría explicar por qué siempre aparece un elemento detallador (un sintagma nominal completo o un pronombre) en los sintagmas posposicionales ergativos con la posposición -tí (las otras posposiciones en malecu pueden ir acompañadas por un prefijo verbal de la serie absolutiva sin ningún elemento detallador): si no fuera necesario codificar el participante ergativo por medio de un sintagma nominal completo o un pronombre en la cláusula en cuestión, tampoco sería necesario orientar la cláusula al ergativo, ya que no existiría ambigüedad en cuanto a la referencia del elemento que codifica el participante ergativo.

Además, la orientación al ergativo parece ser un recurso mucho más común en malecu para indicar el caso gramatical de los sintagmas nominales detalladores que el orden de los constituyentes en su colocación básica. En el cuadro 4 se muestra el número de cláusulas en el corpus que presentan 0,1 y 2 argumentos verbales explícitos (expresados mediante un sintagma nominal completo o un pronombre), respectivamente. La primera columna indica el número de argumentos explícitos; la segunda, el número de cláusulas en el corpus que presentan el número de argumentos explícitos indicado en la primera columna; y la tercera columna, la distribución porcentual. Como se puede observar, solo dos cláusulas en todo el corpus presentan dos argumentos explícitos (y, como se verá más adelante, en ninguna de las dos aparecen ambos sintagmas nominales en su posición básica a la izquierda del verbo).

Cuadro 4. Número de argumentos verbales explícitos en cada cláusula del corpus.

\begin{tabular}{|l|l|l|}
\hline & \multicolumn{2}{|c|}{ Total } \\
\hline 0 & 754 & $56,7 \%$ \\
\hline 1 & 574 & $43,2 \%$ \\
\hline 2 & 2 & $0,2 \%$ \\
\hline
\end{tabular}

\subsection{La topicalidad de los participantes ergativos}

Como se ha mencionado, Constenla (1986) afirma que la orientación al ergativo se emplea cuando el participante ergativo se introduce o se reintroduce como tópico. Con el fin de comprobar esta afirmación, se llevó a cabo un análisis cuantitativo de la topicalidad de los participantes expresados mediante diferentes funciones sintácticas. Si la hipótesis de Constenla fuera correcta, los participantes ergativos en cláusulas orientadas al ergativo deberían presentar considerablemente mayor topicalidad que los otros participantes.

"Tópico" es un término que ha recibido diferentes definiciones, tales como "acerca de lo que habla la cláusula" y "acerca de lo que habla el discurso" (Payne 1997: 270). Givón (2001b: 253-4), por su lado, define "topicalidad" como una propiedad pragmática pertinente al participante o a los participantes de los que trata la información proposicional 
de las cláusulas, normalmente expresados por medio de categorías nominales; además, cuando algún evento o estado presenta topicalidad, suele nominalizarse (Givón 2001b: 254). Los participantes más recurrentes e importantes a lo largo del discurso son los más topicales. Por lo tanto, de acuerdo con esta perspectiva, la topicalidad es una propiedad gradual y relativa, y todos los participantes nominales son topicales en cierto grado. Esta definición se distingue de la que sigue Constenla (1986), la cual no incluye un aspecto cuantitativo y no parece tratar la topicalidad como una propiedad gradual, sino binaria.

Es importante señalar que, de acuerdo con Givón (2001b: 254), un participante no es topical por el hecho de ser codificado como tal, sino por ser recurrente a lo largo del discurso. La codificación gramatical de tópicos se hace principalmente para ayudar al oyente a centrar la atención en los participantes más importantes, puesto que la atención es una capacidad mental limitada (Givón 2001a: 198).

El análisis cuantitativo de topicalidad se llevó a cabo midiendo la "persistencia catafórica" de los referentes; es decir, su persistencia en las cláusulas subsiguientes. Givón (2001a: 198, 457; 2001b: 255) describe el método de la siguiente manera: Por cada aparición de una referencia de un participante, se cuenta el número de veces que aparecen elementos correferenciales en las próximas diez cláusulas; un alto número significa mayor persistencia catafórica y mayor grado de topicalidad. Givón (2001a: 199) clasifica un referente que se vuelve a mencionar dos o menos veces como "menos topical" y uno que se vuelve a mencionar más de dos veces como "topical". Después del conteo, se calculan los porcentajes de referentes "topicales" y "menos topicales”, según su función sintáctica.

En las mediciones de la persistencia topical, solo se analizaron las referencias de participantes de tercera persona. Dado que, según Constenla (1986, 1998), las referencias a primera y segunda persona nunca se expresan por medio de estrategias más explícitas que un pronombre personal, se habrían distorsionado los resultados de los análisis cuantitativos si estas referencias se hubieran tomado en cuenta.

Se calculó la persistencia catafórica de los participantes expresados por medio de diferentes funciones sintácticas. En el cuadro 5, S (absolutivo) es el único argumento verbal de una cláusula intransitiva, $\mathrm{P}$ (absolutivo) es el argumento verbal menos agentivo de una cláusula transitiva, A (ergativo) es el argumento verbal más agentivo de una cláusula transitiva, y E es el participante ergativo en una cláusula orientada al ergativo:

Cuadro 5. Número de participantes "topicales" y "menos topicales" en el corpus, según su función sintáctica.

\begin{tabular}{|l|l|l|l|l|l|l|l|l|}
\hline & \multicolumn{2}{|c|}{ S } & \multicolumn{2}{c|}{ P } & \multicolumn{2}{c|}{ A } & \multicolumn{2}{c|}{ E } \\
\hline Topical & 315 & $57,6 \%$ & 161 & $65,8 \%$ & 227 & $65,8 \%$ & 37 & $66,1 \%$ \\
\hline Menos topical & 232 & $42,4 \%$ & 232 & $59,0 \%$ & 118 & $34,2 \%$ & 19 & $33,9 \%$ \\
\hline
\end{tabular}

De los tres roles S, A y P, el de A (el ergativo) es el que mayor persistencia topical presenta. En total, el $65,8 \%$ de los participantes ergativos de las cláusulas no orientadas al ergativo se clasificaron como "topicales". Los participantes expresados por medio de un sintagma posposicional en las cláusulas orientadas al ergativo presentan casi exactamente la misma persistencia topical que los ergativos de las cláusulas no orientadas. Este hecho indica que el caso ergativo tiende a presentar el mismo nivel de topicalidad independientemente de si la cláusula es orientada o no orientada al ergativo, por lo que la función principal de la orientación al ergativo no parece ser la de marcar mayor topicalidad. Sus funciones serán analizadas con más detalle de manera cualitativa en el siguiente apartado. 


\section{Análisis cualitativo}

\subsection{Cláusulas subordinadas de relativo}

Las cláusulas subordinadas de relativo ofrecen muy buenos ejemplos del uso de la orientación al ergativo como estrategia desambiguadora. Estas contienen el pronombre relativo $o$, el cual en teoría puede referirse al participante ergativo o al absolutivo cuando la cláusula es transitiva. Sin embargo, en todos los casos observados en los que este pronombre se refiere al ergativo, la cláusula subordinada en la que aparece es orientada al ergativo, por lo que el pronombre relativo siempre toma la forma óti (con el sufijo - $t i$, que marca el ergativo) cuando se refiere al participante ergativo. En el ejemplo 12 (Constenla, Castro y Blanco 1993: 68;45-46) aparecen una cláusula semánticamente transitiva subordinada en la que el pronombre relativo tiene la función de ergativo (12b), por lo que se orienta al ergativo, y una intransitiva en la que el pronombre relativo, naturalmente, tiene la función de absolutivo (12c):

(12) a. Naí-to tafinh aquel-F (3)-quedar

"Quedará al mando"

b. ó-ti taclhacá orróqui uráje, que-ERG mucho cosa (3)-saber.MR "el que sepa más (cosas),"

c. ó juactené yaj i-a-nhe ní co úpal. que primero llegado 3-ser-MR este (3)-en casa "quien haya llegado primeramente a la casa."

En el ejemplo 13 (Constenla, Castro y Blanco 193: 82;535-536), el significado del verbo utilizado en las dos cláusulas es transitivo, pero en 13a, el verbo aparece en antipasiva, por lo que la cláusula es sintácticamente intransitiva, y el agente de la acción, representado por $o$, es de caso absolutivo. No obstante, el mismo evento se repite, esta vez expresando explícitamente al sapo en una cláusula transitiva. Ahora el pronombre relativo se refiere al participante ergativo sintáctico, y la cláusula se orienta al ergativo.

(13) a. ní cuá-fa ó f-úji-tó-ye este (3)-por-ENF que (3)-AP-mandar-ir-MR "por obra del que (lo) envió"

b. ó-ti lucúlucu úji-tó-ye que-ERG sapo (3)-mandar-ir-MR “(d)el que envió al sapo”

\subsection{Orientación al ergativo con participantes ergativos activos}

Como se ha visto, Constenla (1986: 126) afirma que la orientación al ergativo se emplea cuando el ergativo "representa un participante en el hecho narrado que es al mismo tiempo 'nuevo' y el tópico de una de las cláusulas que pertenecen a la línea argumental básica de la narración". No obstante, en el análisis cuantitativo se demostró que los participantes 
ergativos de las cláusulas orientadas no presentan mayor topicalidad (en los términos de Givón) que aquellos de las cláusulas no orientadas. En el análisis cualitativo, se encontró una serie de ejemplos que no concuerdan con la afirmación de Constenla.

El ejemplo 14 es uno de los más claros de que la orientación al ergativo no indica ni topicalidad (siempre según la definición de Givón (2001a, 2001b)) ni que el participante sea nuevo. Después de la cláusula orientada al ergativo en $14 \mathrm{f}$, no se vuelve a mencionar el participante en mucho tiempo, por lo que su función no puede ser una marcación catafórica de topicalidad, y el participante no es nuevo pues ha sido mencionado en las cinco cláusulas anteriores.

(14) a. 'Ninhá-fa-tó pó mi-túfi anh, así-ENF-F 2 2-pavón (3)-ser

"'Así serán tus pavones,"

b. épe-tó me mi-túfi maráma ri-anh.

NEG-F NEG 2-pavón PL (3)-bañar

"no se bañarán tus pavones."

c. Acá-fa-tó mi-túfi maráma purú úje punh cúta cuinhca óra inh.

Mal-ENF-F 2-pavón PL (3)-cuerpo (3)-oler.FORM estar murciélago (3)-ala DIM

(3)-como

"El cuerpo de tus pavones olerá mal como alita de murciélago."

d. Épe-tó me mi-túfi maráma ri-anh.

NEG-F NEG 2-pavón PL (3)-bañar

"No se bañarán tus pavones."

e. Quinhílhi-quinhílhi-fá-to mi-túfi maráma unh.

con.la.cara.ajada-con.la.cara.ajada-ENF-F 2-pavón PL (3)-andar

"Andarán con el rostro ajado tus pavones."

f. Épe-tó me mi-túfi maráma-tí cajúli chía.'

NEG-F NEG 2-pavón PL-ERG chocolate (3)-beber

"Tus pavones no beberán chocolate."”

La misma estructura aparece en el siguiente ejemplo (Constenla, Castro y Blanco 1993: 81;478-481). En este caso, las tres cláusulas en cuestión son semánticamente transitivas, y todas son orientadas al ergativo:

(15) a. 'Puá, ninhá-fa-tó na-túfi maráma-tí mi-lhá purú yu p-sainh.

bah así-ENF-F 1E-pavón PL-ERG 2-sobre ceniza (3)-con (3)-AP-regar

"'Bah, mis pavones te regarán ceniza encima también."

b. Épe-tó-me na-túfi maráma-tí pué mi-cuanh ninhá-fa.'

NEG-F-NEG 1E-pavón PL-ERG bien 2-ver también-ENF

"Mis pavones no te verán bien."

c. I-quí óyu ninhá-fa ninhca maráma-tí jó-ye

3-decir que-con así-ENF como.este PL-ERG (3)-hacer-MR

"Se dice que por esta causa, así hacen ellos" 
Otro ejemplo de que la orientación al ergativo no indica que el referente sea nuevo se muestra a continuación (Constenla, Castro y Blanco 1993: 91;829-831). Tafá 'el jaguar' se menciona en 16a como argumento absolutivo, pero las dos cláusulas siguientes son orientadas al ergativo, probablemente porque el participante ergativo, el jaguar, es explícito. El motivo de la expresión explícita en este caso parece ser un recurso retórico, probablemente pertinente al género literario en cuestión (Krohn 2012).

(16) a. Tafá tócufá i-lhá maráma pítequí toí-nhe, jaguar AUM 3-sobre PL (3)-salir pasar-MR "Les salió un gran jaguar,"

b. chí tafá-t i-turé maráme.

Todo jaguar-ERG 3-exterminar PL

"a todos los mató el jaguar."

c. Tafá-t i-canh maráme. jaguar-ERG 3-comer PL.MR

"El jaguar los devoró."

\subsection{Orientación al ergativo con participantes ergativos poco topicales}

En los resultados del análisis cuantitativo, se vio que los participantes ergativos muestran mayor grado de topicalidad que los absolutivos, por lo que no es de extrañar que los participantes ergativos en las cláusulas orientadas sean altamente topicales en muchas ocasiones. No obstante, este no siempre es el caso.

En 17 (Constenla, Castro y Blanco 1993: 73;236), una cláusula orientada al ergativo, el participante ergativo, lhalac 'serpiente', no se vuelve a mencionar en el discurso y tampoco se puede considerar particularmente importante en la línea argumental básica de la narración, por lo que no cumple con la definición de tópico de Constenla:

(17) Paí-to malécu maráma lhalac-t i-cué-cú.

ahora-F persona PL serpiente-ERG 3-matar-IT

"A los indios los matarán las serpientes."

Se puede observar algo similar en 18 (Constenla, Castro y Blanco 1993: 88;718), donde el participante ergativo, Tócu 'el dios', no se vuelve a mencionar en la narración. Sin embargo, si se ampliara la definición de topicalidad para que también incluya participantes muy importantes aunque no recurrentes en las próximas cláusulas (una posibilidad discutida más adelante), sí podría considerarse topical.

(18) Ta-cá ní-t i-coquí taíqui-yé Tócu,

y-SUC este-ERG 3-boca (3)-oír-MR dios

"Y el dios atendió sus súplicas,"

Los participantes animados suelen ser los más topicales, pero, en la cláusula orientada al ergativo en el ejemplo 19 (Constenla, Castro y Blanco 1993: 87;704), el participante ergativo, cóli 'diarrea', ni siquiera es animado. Además, según la definición de topicalidad empleada por Constenla, el tópico de esta cláusula sería 'todos', no 'diarrea': 
(19) ta-cá ála cóli-ti jué maráme

y-SUC todo diarrea-ERG (3)-hacer PL.MR

"y a todos les dio diarrea"

Ahora bien, el análisis de la orientación al ergativo de Constenla (1986) encaja bien con los fenómenos observados en el texto que él examinó, pero se trata de un corpus muy limitado. De hecho, incluye solo tres cláusulas orientadas al ergativo, y no es raro que un actante ergativo presente los rasgos de 'nuevo' y 'tópico', sobre todo si se toma en cuenta que los actantes ergativos de por sí tienden a ser más topicales que los demás. Es muy importante volver a subrayar que las definiciones de tópico de Givón y de Constenla son distintas: la diferencia principal estriba en el hecho de que la de Givón incluye un aspecto cuantitativo, mientras que la de Constenla no. Por ello, el que se muestre que la orientación al ergativo no marca topicalidad en el sentido de Givón no implica directamente que no lo marque en el sentido de Constenla. No obstante, se ha observado que muchos de los actantes marcados con - $t i$ tampoco son tópicos según la definición aplicada por Constenla.

El texto analizado en Constenla (1986) presenta dos cláusulas no orientadas con el argumento ergativo explícito. De todas formas, en ambas cláusulas en cuestión (20 y 21) (Constenla 1986: 123), también es explícito el actante absolutivo, y ninguno de los dos sintagmas se desplaza a la derecha, por lo que el orden de los constituyentes marca los casos gramaticales, así que no hace falta marcar el caso ergativo de otra manera:

(20) Tafá Querrélhiquífa filhí rri-maré-maré.

jaguar Querrélhiquífa ojo (3)-3erg-engañar-IT

"El jaguar engañó a Querrélhiquífa."

(lit: "El jaguar engañó al ojo de Querrélhiquifa.”)

(21) ta-cá Querrélhiquífa i-úfa rri-quí-ye,

y-SUC Querrélhiquífa 3-cuñado (3)-3erg-decir-MR

"y Querrélhiquífa le dijo a su cuñado,"

\subsection{Argumentos verbales ergativos explícitos}

En el corpus analizado para el presente trabajo se encontraron solo 12 cláusulas no orientadas al ergativo con el argumento ergativo explícito. En esta sección se tratará de explicar por qué las cláusulas transitivas que presentan un actante ergativo explícito en algunos pocos casos no se orientan al ergativo.

\subsubsection{Cláusulas con dos argumentos explícitos}

En dos de las cláusulas no orientadas con el argumento ergativo explícito, también el participante absolutivo es expresado de manera explícita. Ambas se encuentran en el mismo texto y son las siguientes (Constenla, Castro y Blanco 1993: 91;828, 92;861):

(22) Nán i-quí ninhá-fa amí paquéquirrí-fa maírrinhá-nhe maráma rri-lachó-nhe tafá pá. pues 3-decir así-ENF de.nuevo cuatro-ENF malo-SUST PL (3)-3erg-acabar-MR jaguar ya "Pues se dice que así ya de nuevo atrapó a cuatro malos el jaguar." 
(23) Ta-cá chí curíjurí lhíja maráma juáqui rri-arí-nhe maírrinhá-nhe ní taf. y-SUC todo mujer gente PL cara (3)-3erg-esconder-MR malo-SUST COP jaguar

"Y a todas las mujeres les hizo perder el rostro el diablo del jaguar." (lit: "Y escondió el rostro de todas las mujeres el diablo del jaguar.")

Las dos cláusulas pertenecen a la misma serie de eventos, y tafá 'el jaguar' es claramente uno de los principales tópicos en ambas apariciones. En los dos casos, tafá aparece desplazado a la derecha del verbo sin pronombre sustitutivo a la izquierda de este, lo cual puede indicar que el hablante hasta al final de la cláusula decide expresar el jaguar de manera léxica. Ya se vio en el análisis cuantitativo que tal construcción tiende a marcar alta topicalidad del participante representado por el elemento desplazado. Una hipótesis podría ser que cuando aparecen este tipo de construcciones, el hablante decide, después de haber pronunciado el verbo, mencionar explícitamente al actante ergativo para subrayar su topicalidad, lo cual se hace a expensas de la claridad en cuanto a los casos gramaticales de los referentes. Sin embargo, desde luego, esta explicación requiere de más casos para poderse demostrar.

\subsubsection{Cláusulas con argumento ergativo explícito}

Varias de las cláusulas no orientadas al ergativo con el argumento ergativo explícito en realidad parecen ser el resultado de un desplazamiento del elemento ergativo de la cláusula anterior, la cual es orientada al ergativo. Un fuerte indicio de esto es el hecho de que los argumentos ergativos léxicos tienden a aparecer en cadenas de varias cláusulas seguidas que expresan un mismo evento con el mismo verbo. Por ejemplo, 24a (Constenla, Castro y Blanco 1993: 74;252-253) es orientada al ergativo y el actante ergativo es expresado mediante el pronombre ní en un sintagma posposicional de ergativo. De la misma manera en que este pronombre puede funcionar como elemento sustitutivo para un sintagma desplazado al final de la cláusula, se puede decir que el sintagma correferencial aquí no se encuentra hasta en la cláusula siguiente. La función catafórica del pronombre marcada mediante la posposición ergativa hace referencia a Tócu maráma 'los dioses' en 24b. Teniendo presente la referencia catafórica de ní, no cabe duda para el hablante de que Tócu maráma en $24 \mathrm{~b}$ sea el actante ergativo y no el absolutivo.

(24) a. Ta-cá ní-ni ní-t i-quí, y-SUC esto-COP este-ERG (3)-decir

"Y (ellos) le dijeron,"

b. Tócu maráma rri-quí dios PL (3)-3erg-decir

"los dioses le dijeron"

c. i-rri-quí

3-3erg-decir

"le dijeron"

El mismo fenómeno se observa en el ejemplo número 25 (Constenla, Castro y Blanco 1993: 74;275-276), donde la pluralidad del referente también es marcada en el pronombre del sintagma posposicional ergativo: 
(25) a. Ta-cá ní maráma-tí quí, y-SUC este PL-ERG (3)-decir

"Y (ellos) le dijeron,"

b. Tócu maráma rri-quí dios PL (3)-3erg-decir

"los dioses le dijeron"

Además, el pronombre sustitutivo puede volver a aparecer en la cláusula siguiente, indicando un desplazamiento a la derecha dentro de esa cláusula, como en 26b (Constenla, Castro y Blanco 1993: 75;285-286). De esta forma, las dos apariciones del pronombre sustitutivo en realidad son referencias catafóricas del referente que se explicita de manera léxica al final de la segunda cláusula.

(26) a. ta-cá ní-t i-quí y-SUC este-ERG 3-decir "y les dijo,"

b. ní rri-quí Tóji este (3)-3erg-decir Sol "les dijo el Sol"

En el siguiente ejemplo (Constenla, Castro y Blanco 1993: 106;1388-1389), un actante se explicita en la primera cláusula, pero, puesto que suelen ser los actantes absolutivos los que se explicitan de esta manera, el hablante posiblemente considera necesario aclarar que se trata del ergativo en la siguiente cláusula, orientándola al ergativo.

(27) a. ta-cá rri-quí-ye Aóre Cha Có-nhe, y-SUC (3)-3erg-decir-MR Río.Muerte (3)-Cabecera (3)-en-SUST "y le dijo La de la Cabecera del Aóre ${ }^{4}, "$

b. Aóre Cha Có-nhe-t i-quí:

Río.Muerte (3)-Cabecera (3)-en-SUST-ERG 3-decir

"La de la Cebecera del Aóre le dijo:"

Otro ejemplo de una serie de cláusulas seguidas que contienen el mismo verbo se aprecia en 28 (Constenla, Castro y Blanco 1993: 105;1356-1358). Aquí, ninguno de los actantes del evento verbal se explicita en la primera cláusula. En la segunda, el absolutivo se explicita de manera léxica, mientras que el ergativo se explicita en la tercera cláusula. En este caso tal vez haya una posible ambigüiedad, pero también puede que el oyente automáticamente perciba el primer elemento léxico (en 28b) como referente del absolutivo, por lo que el segundo (en 28c) necesariamente se entiende como referente del ergativo.

(28) a. Ta-cá rri-quí, y-SUC (3)-3erg-decir

"Y le dijo,"

b. i-urílhifá rri-quí-ye,

3-hija (3)-3erg-decir-MR

"le dijo a su hija" 


\section{c. Nharíne Cha Có-nhe rri-quí \\ Río.Venado (3)-Cabecera (3)-en-SUST (3)-3erg-decir \\ "El de la Cabecera del Nharíne le dijo"}

Por último, se encontraron un par de cláusulas en las que el oyente no tiene otro medio más que el contexto para entender que el participante explicitado es el ergativo: 29c (Constenla, Castro y Blanco 1993: 109;1502-1505) y 30 (Constenla, Castro y Blanco 1993: 112;1603-1604). Lo anterior muestra que la orientación al ergativo no siempre se aplica en tales casos. En el ejemplo 29 es posible que el hablante considere que el contexto discursivo es suficiente para que el oyente identifique la función de Aóre Cha Cónhe. Por su parte, en 30, el hablante probablemente decide explicitar el referente después de haber pronunciado el verbo, dada la pequeña pausa representada por la coma.

(29) a. Ta-cá rri-quí:

y-SUC (3)-3erg-decir

"Y le dijo:"

b. 'Máranh, paí-to ma-tué Ucúriquí Chichá Afárasufá ri-té-juríma,' he.aquí ahora-F 1I-ir Río.Frío (3)-Rabadilla (3)-Vigilante (3)-1Ierg-ALEJ-visitar " Mira, visitemos hoy a La que Vela por el Curso Medio de Ucúrinh."”

c. ní rri-quí-ye Aóre Cha Có-nhe éste (3)-3erg-decir-MR Río.Muerte (3)-Cabecera (3)-en-SUST "Esto le dijo La de la Cabecera del Aóre."

(30) Ta-cá i-cuá ninhá-fa chí rri-canh maráme, malécu maráma. y-SUC 3-por así-ENF todo (3)-3erg-comer PL.MR persona PL "Y por eso así todas la comen, las personas."

\subsubsection{Otra estrategia para evitar argumentos ergativos explícitos}

La orientación al ergativo no es la única estrategia que se utiliza para evitar la ambigüiedad producida por un argumento ergativo explícito. Otra estrategia frecuentemente usada, aunque menos común que la orientación al ergativo, aparece en cláusulas que contienen el verbo quí, el cual puede ser intrasitivo o transitivo. En varias ocasiones aparece con significado intransitivo en la primera cláusula, con el único argumento (el absolutivo) explícito. En la segunda cláusula aparece con significado transitivo, explicitando el argumento absolutivo de este evento (en malecu, el actante absolutivo del verbo 'decir' es al que se habla, contrario que en español, lengua en la que el objeto directo es lo que se dice). De esta manera, se evita la posible ambigüedad al expresar los dos actantes del evento verbal con el caso absolutivo. Un ejemplo de esta estrategia se ve en 31 (Constenla, Castro, Blanco 1993: 101;1228-1230):

(31) a. Ta-cá ní-ni ní quí Nharíne Cha Có-nhe, y-SUC esto-COP este (3)-decir Río.Venado (3)-Cabecera (3)-en-SUST "Y dijo El de la Cabecera del Nharíne,"

b. ní rri-quí-ye Ucúriquí Chichá Afárasufá, este (3)-3erg-decir-MR Río.Frío (3)-Rabadilla (3)-Vigilante "le dijo a La que Vela por el Curso Medio del Ucúrinh," 


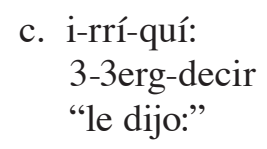

La misma estrategia se observa en 32 (Constenla, Castro y Blanco 1993: 73;212-213), donde el hablante no considera necesario explicitar el actante absolutivo:

(32) a. Ta-cá Tóji i-quí, y-SUC Sol 3-decir

"Y el Sol dijo,"

b. i-rri-quí:

3-3erg-decir

"les dijo:"

\section{Conclusiones}

Se ha observado que los participantes ergativos en cláusulas orientadas al ergativo no son más topicales, en los términos de Givón, que los de las cláusulas no orientadas. Además, muchas veces se trata de referentes que se encuentran en estado activo, lo cual no concuerda con lo descrito por Constenla (1986: 126), quien afirma que la orientación al ergativo se emplea cuando el participante ergativo “es al mismo tiempo 'nuevo' y el tópico de una de las cláusulas que pertenecen a la línea argumental básica de la narración”. En realidad, la orientación al ergativo se explica mejor como una estrategia para evitar la ambigüedad en cuanto al referente, ya que constituye una marcación explícita del caso ergativo. De hecho, la gran mayoría de las cláusulas que incluyen referencias explícitas de los participantes ergativos, sea mediante elementos léxicos o pronombres, son orientadas al ergativo. Es probable que este desacuerdo con las conclusiones de Constenla (1986) se deba a la cantidad de cláusulas analizadas y tal vez, en parte, a las diferentes definiciones de los términos "tópico" y "topicalidad".

Cuando aparece solo un sintagma nominal o un pronombre de tercera persona en una cláusula transitiva no orientada, este elemento casi siempre representa el participante absolutivo. Puesto que el único tipo de marcación de casos que puede darse en una cláusula no orientada (el orden respectivo de los sintagmas del ergativo y del absolutivo) solo es posible cuando los dos sintagmas están presentes, lo cual es poco frecuente, la orientación al ergativo constituye un recurso más accesible para explicitar que un sintagma nominal o un pronombre se refiere al participante ergativo y no al absolutivo.

Para confirmar los resultados de estos análisis, sería conveniente estudiar el mismo fenómeno en más textos, sobre todo textos de otras clases de comunicación lingüística.

\section{Abreviaturas}

Las abreviaturas utilizadas en el presente trabajo están basadas en las de Constenla (1998).

- $\quad$ Linde de morfema

- Separa significados del español que en conjunto traducen un solo elemento malecu

(X) El morfema $\mathrm{X}$ no se manifiesta fónicamente (es un alomorfo cero)

1E Primera persona exclusiva, absolutivo

1Eerg Primera persona exclusiva, ergativo 
1Esg Primera persona exclusiva, singular

1Epl Primera persona exclusiva, plural

1I Primera persona inclusiva, absolutivo; o pronombre de primera persona inclusiva

1Ierg Primera persona inclusiva, ergativo

2 Segunda persona, absolutivo; o pronombre de segunda persona

2erg Segunda persona, ergativo

3 Tercera persona, absolutivo

3erg Tercera persona, ergativo

AUM Aumentativo

ALEJ Alejamiento

CONM Conmiserativo

COP Cópula

ENF Enfático

ERG Posposición ergativa

F $\quad$ Futuro mediato

FORM Formativo de formas verbales complejas

IT Iterativo

MR Modo real

NEG Negación

PL Plural

SUC Marcador de sucesión en el tiempo

SUST Sustantivador

\section{Notas}

1. Las abreviaturas y convenciones de transcripción se encuentran en el apartado Abreviaturas.

2. Este libro constituye una de las colecciones más extensas de narraciones en malecu: once en total. El último texto fue excluido del corpus porque consiste principalmente en una serie de mandamientos de los dioses en forma de cláusulas imperativas con pocos referentes recurrentes a lo largo del discurso, por lo que no resulta adecuado para un análisis del mantenimiento de la referencia discursiva.

3. Según la religión tradicional malecu, el Sol es un ser de figura humana que se identifica como el dios de los blancos (Constenla, Castro y Blanco 1993: 48).

4. La de la Cabecera del Aóre, El de la Cabecera del Nharíne y La que Vela por el Curso Medio del Ucúrinh son tres de los dioses de la religión tradicional malecu.

\section{Bibliografía}

Barrantes, Ramiro, María Eugenia Bozzoli de Wille y Patricia Gudiño. 1986. Memorias del primer simposio científico sobre pueblos indígenas de Costa Rica. San José: Consejo Nacional de Investigaciones Científicas y Tecnológicas.

Constenla Umaña, Adolfo. 1986. "La función de una alternativa gramatical guatusa en el discurso narrativo tradicional”. En: Barrantes et al. (Comps.), 119-128.

1998. Gramática de la lengua guatusa. Heredia: Editorial de la Universidad Nacional.

Constenla Umaña, Adolfo, Eustaquio Castro C. y Antonio Blanco R. 1993. Laca majifijica. La transformación de la tierra. San José: Editorial de la Universidad de Costa Rica. 
Du Bois, John W. 1987. "The discourse basis of ergativity”. Language. 64: 805-855.

Givón, Talmy. 2001a. Syntax. Vol. I. Amsterdam: John Benjamins.

2001b. Syntax. Vol. II. Amsterdam: John Benjamins.

Krohn, Haakon Stensrud. 2012. "El mantenimiento de la referencia anafórica en el discurso narrativo tradicional en lengua malecu". Revista de Filología y Lingüística de la Universidad de Costa Rica. 38 (1): 191-216.

Payne, Thomas. 1997. Describing morphosyntax. Cambridge: Cambridge University Press. 